\title{
Financial development and economic growth: an empirical investigation of the role of banks and institutional investors
}

\author{
LAURent CAVENAILE ${ }^{a, *}$ AND DANIELle SOUGNe ${ }^{b}$
}

\begin{abstract}
This paper gives a new light on the finance-growth nexus through the investigation of the role of institutional investors as providers of risk diversification in the process of economic growth. We make use of panel cointegration techniques to study the potential long run relationship between economic growth, banking development and institutional investors in 6 OECD countries. Our results highlight some heterogeneity in the long run relationship between financial development and growth. Institutional investors are shown to support long run economic growth in only 2 countries. We also report a negative long run relationship between both indicators of financial development.
\end{abstract}

Keywords: Economic growth, Banks, Institutional investors, Panel cointegration, Causality.

JEL: E44, G20, O16.

${ }^{a}$ HEC-Management School, University of Liège. Rue Louvrex, 14 (N1) - 4000 Liège, Belgium.

${ }^{\mathrm{b}}$ HEC-Management School, University of Liège. Rue Louvrex, 14 (N1) - 4000 Liège, Belgium.

* Corresponding author. Email: Laurent.Cavenaile@ulg.ac.be 


\section{Introduction}

The role of finance in economic development has been quite extensively investigated from both a theoretical and empirical point of view since the work of Schumpeter (1912). Unlike Schumpeter who considers financial development as a source of economic growth, Robinson (1952) suggests that the financial sector simply responds to the need of financial intermediation created by the expansion of the real sector of the economy. These conflicting views respectively correspond to the supply-leading and demand-following hypotheses regarding the direction of the causality between financial and economic development. Proponents of the supplyleading hypothesis argue that the development of financial intermediaries can lead to economic growth through increased capital accumulation ${ }^{c}$ (see for instance Pagano (1993)) and/or through enhanced technological change. There are several reasons why the development of financial intermediaries may lead to improved productivity. King and Levine (1993a) suggest that the evaluation of investment projects which is characterized by large fixed cost is more efficiently performed by specialized institutions like banks. Moreover, once productive investment opportunities are selected, they may require large amounts of funds which can be more easily pooled by financial intermediaries than by individual savers. In addition, more productive investments are traditionally characterized by higher levels of risk. By allowing diversifying idiosyncratic and liquidity risk, financial intermediaries can help modifying fund allocation in favour of more productive investments which in

\footnotetext{
${ }^{\mathrm{c}}$ The effect of risk mitigation provided by financial institutions on the saving rate is nevertheless ambiguous and depends on the relative intensity of income and substitution effects (see Devereux and Smith (1994) and Levine (1997)).
} 
turn results in increased economic growth (Greenwood and Jovanovic (1990) and Bencivenga and Smith (1991)). Levine (1991), Saint-Paul (1992) and Greenwood and Smith (1997) develop theoretical models in which stock markets are shown to perform a role of risk diversifier similar to the one of banks and hence can also positively affect long run economic development. During the last two decades, the link between financial development and economic growth has been extensively investigated from an empirical point of view. A large part of the empirical literature finds a positive relationship going from banking sector development (for instance King and Levine (1993b), Gregorio and Guidotti (1995), Levine et al. (2000) and Christopoulos and Tsionas (2004)) and stock market development (see for instance Atje and Jovanovic (1993), Levine and Zervos (1998) Rousseau and Wachtel (2000)) to economic growth. On the other hand, several studies conclude to the existence of a bi-directional relationship between financial development and economic growth in which they both positively influence each other (Demetriades and Hussein (1996) and Luintel and Khan (1999)). While the existing literature has exclusively focused on banking and stock market development, there are several other institutions or investments vehicles which may also have an impact on economic development through improved risk mitigation and fund pooling. Levine (1997) cites for instance mutual funds, option, futures and other derivatives as potential risk diversifiers which may perform the same role with respect to economic development as banks and stock markets. However, the impact of these institutional investors and derivatives has not been investigated in the empirical literature yet. In this context, this is the aim of this paper to extend the existing 
empirical literature which exclusively focuses on banks and stock markets to the potential role of institutional investors in promoting long run economic growth.

The paper is structured as follows. In the next section, we present our data and methodology. We then report our empirical results and conclude.

\section{Data and methodology}

We study the potential causality which may exist between economic growth, banking development and institutional investors. The inclusion of banking development in our trivariate system allows us to test whether institutional investors may offer different services in terms of saving allocation and risk mitigation from banks and whether they may have significant impact on long run economic growth when we control for the role of bank credit. We use the logarithm of real GDP per capita (GDP) for economic growth, private credit by deposit money banks and other financial institutions over GDP (BANK) for the development of the banking sector and financial assets held by institutional investors as a percentage of GDP (INST) for institutional investors. The first two variables are retrieved from the

World Bank World Development Indicators Database and data on institutional investors come from the OECD statistics database. Institutional investors include investment funds, insurance companies, pension funds and other of institutional savings as defined by the OECD. Data are available for only 6 OECD countries 
(Belgium, Canada, Chile, Japan, Spain and United States) between 1980 and 2008 (29 annual observations) ${ }^{d}$.

We follow the same test procedure as Cavenaile et al. (2011) who investigate causality between banks and stock market development and economic growth for developing countries. Before we test causality within our trivariate system, we must check the characteristics of our series and more particularly their order of integration. I(1) series would lead us to use panel cointegration techniques. Consequently, we first test the presence of a unit root in our series using the panel unit root test proposed by Pesaran (2007). This test enables us to take into account cross-country correlation through a single common factor. Pesaran (2007) shows that this single common factor can be proxied by the cross-sectional mean of the tested variable. Individual unit root test statistics $\left(t_{\varphi \mathrm{i}=0}\right)$ can be obtained from the cross-sectionally augmented Dickey Fuller equation assuming an $A R(p)$ error structure:

$\mathbf{\Delta} y_{i t}=\alpha_{i}+\varphi_{i} y_{i t-\mathbf{1}}+c_{i} \bar{y}_{t-\mathbf{1}}+\sum_{j=\mathbf{0}}^{p} d_{i j} \mathbf{\Delta} \bar{y}_{t-\mathbf{1}}+\sum_{j=\mathbf{1}}^{p} \delta_{i j} \mathbf{\Delta} y_{i t-\mathbf{1}}+\varepsilon_{i t}$

where $\bar{y}_{t}=\frac{1}{N} \sum_{j=1}^{N} y_{j t}$.

\footnotetext{
${ }^{d}$ Data availability on institutional investors and the length required from time series to achieve convergence in our panel cointegration methodology constrained our choice to those 6 OECD countries.
} 
Panel unit root test can then be derived from the individual test statistics following the methodology proposed by Im et al. (2003). More particularly, Pesaran (2007) proposed the CIPS statistics as:

CIPS $=\frac{1}{N} \sum_{i=1}^{N} t_{\varphi i=0}$

Pesaran (2007) provides the corresponding critical value tables.

Regarding cointegration analysis, we use the panel methodology proposed by Groen and Kleibergen (2003). This Johansen-like approach is a panel cointegration test and estimation procedure which allows the existence of cross-country contemporaneous correlation. ${ }^{e}$ Groen and Kleibergen (2003) focus on the following representation:

$\Delta \mathbf{Y}_{\mathbf{t}}=\left(\begin{array}{ccccc}\Pi_{1} & 0 & \cdots & 0 & 0 \\ 0 & \Pi_{2} & 0 & \cdots & 0 \\ \vdots & & \ddots & & \vdots \\ 0 & & & & 0 \\ 0 & 0 & \cdots & 0 & \Pi_{\mathbf{N}}\end{array}\right) \mathbf{Y}_{\mathrm{t}-1}+\Lambda \mathrm{W}_{\mathrm{t}}+\epsilon_{\mathrm{t}}=\Pi_{A} \mathrm{Y}_{\mathrm{t}-1}+\Lambda \mathrm{W}_{\mathrm{t}}+\epsilon_{\mathrm{t}}$

where $\mathbf{Y}_{t-1}$ is a Nxk ( $k$ is the number of variables) column vector and $\mathbf{W}_{t}$ is a matrix containing lagged differences.

\footnotetext{
${ }^{\mathrm{e}}$ Cross-unit cointegration is however not possible under this methodology.
} 
In our analysis, variables are set in the order GDP, BANK and INST. The variancecovariance matrix of the error terms allows the presence of cross-unit contemporaneous dependence:

$\Omega=\left(\begin{array}{ccc}\Omega_{11} & \cdots & \Omega_{1 \mathrm{~N}} \\ \vdots & \ddots & \vdots \\ \boldsymbol{\Omega}_{\mathrm{N} 1} & \cdots & \boldsymbol{\Omega}_{\mathrm{NN}}\end{array}\right)$

If the variables are cointegrated and the cointegrating vectors are allowed to be heterogeneous across individuals, the system can be rewritten as:

$\Delta Y_{t}=\left(\begin{array}{ccccc}\alpha_{1} \beta_{1} & 0 & \cdots & 0 & 0 \\ 0 & \alpha_{2} \beta_{2} & 0 & \cdots & 0 \\ \vdots & & \ddots & & \vdots \\ 0 & & & 0 \\ 0 & 0 & \cdots & 0 & \alpha_{N} \beta_{N}\end{array}\right) Y_{t-1}+\Lambda W_{t}+\epsilon_{t}=\Pi_{B} Y_{t-1}+\Lambda W_{t}+\epsilon_{t}$

where $\Pi_{B}$ is of reduced rank $\mathrm{N} \times \mathrm{r}$ with $\mathrm{r}<\mathrm{k}$.

We can normalize the cointegrating vector for country $i$ as:

$\beta_{i}=\left(\begin{array}{c}I_{r} \\ \beta_{i, \mathbf{2}}\end{array}\right)$

where $I_{r}$ is an $r x r$ identity matrix and $\beta_{i, \mathbf{2}}$ is $(k-r) \times r$ matrix.

Consistent maximum likelihood estimates of $\Pi$ and $\Omega$ can be obtained through a stepwise maximization of the log-likelihood function. The number of cointegrating 
vectors (common to all individuals) can also be sequentially tested using the likelihood ratio in Equation (7) test starting with $r=0$ and progressively increasing $r$ until non-rejection of the null hypothesis.

$L R\left(\Pi_{B} \mid \Pi_{A}\right)=T\left[\ln \left|\Omega\left(\Pi_{B}\right)\right|-\ln \left|\Omega\left(\Pi_{A}\right)\right|\right]$

Groen and Kleibergen (2003) derive the asymptotic distribution of the test which is a function of Brownian motion. Critical values can be calculated using Monte Carlo simulations as suggested in Johansen (1995, chapter 15) and Groen and Kleibergen (2003).

The third step of our analysis consists in testing potential long run causality between the three variables in our VECM. We follow the methodology proposed by Toda and Phillips $(1993,1994)$. More particularly, we focus on long run causality i.e. we focus our attention on the cointegrating relationship. In this context, Toda and Phillips $(1993,1994)$ suggest a stepwise methodology. To test long run causality from one variable $x$ on another variable $y$ in a Vector Error Correction Model, we first test the weak exogeneity of the variable $y$ and the significance of the coefficient(s) in the cointegrating vector related to the variable $x$. Toda and Phillips (1994) show that these tests are both $\chi_{r}$ distributed. If both tests reject the null hypothesis and if $r>1$, we further test the significance of the coefficient in $\alpha_{i} \beta_{1}$ which relates $x$ to $y .{ }^{f}$ If all the three tests respectively reject their null hypothesis,

\footnotetext{
${ }^{\mathrm{f}}$ That is the coefficient in $\alpha_{i} \boldsymbol{\beta}_{1}$ related to $x$ in Equation (5) with $y$ as the dependent variable. This test is $\chi_{1}$ distributed.
} 
we can conclude to a significant long run causality running from variable $x$ to variable $y$.

\section{Results}

\section{Panel unit root tests}

Before investigating the existence of potential cointegration relationships between banking development, institutional investors and economic growth, we test the integration order of these three variables. We use the Pesaran (2007) panel unit root tests. Results of the tests are reported in Table 1. Following the Pantula principle, we first test the presence of a unit root in second differences, then in first differences and lastly in levels. We include no deterministic term in the regression for second differences, an intercept only for first differences and an intercept and a trend for level series. Lag selection is based on information criteria. The results conclude to the absence of a unit root in both second and first differences but do not reject a unit root in levels and hence to all three series being I(1).

Table 1: CIPS unit root test statistics

\begin{tabular}{lcccccc} 
& & & \multicolumn{3}{c}{ Critical values } \\
& GDP & BANK & INST & $10 \%$ & $5 \%$ & $1 \%$ \\
\hline 2nd Diff $(D=0)$ & -4.50 & -3.53 & -3.15 & -1.57 & -1.72 & -1.98 \\
Diff $(D=1)$ & -2.80 & -2.33 & -2.53 & -2.21 & -2.33 & -2.57 \\
Levels $(D=2)$ & -2.36 & -1.24 & -1.76 & -2.73 & -2.86 & -3.10 \\
\hline
\end{tabular}

Notes: $\mathrm{D}=0,1,2$ respectively indicate the inclusion of no deterministic term, of an intercept only and of an intercept and a trend in the regression. Lag selection is based on the Bayesian Information Criteria. 


\section{Panel cointegration test and estimation}

Given the order of integration of the three variables, we test for the presence of one or more cointegrating relationships between GDP, BANK and INST. We make use of the Groen and Kleibergen (2003) methodology which is a Johansen-like panel cointegration test allowing for the presence of cross-country contemporaneous correlation. This enables us to test for the number of cointegrating vectors instead of making the assumption of a single vector as in residual-based cointegration analysis. We start with $r=0$ and progressively increase $r$ until non-rejection of the null hypothesis. The first value of $r$ for which we do not reject the null hypothesis determines the number of cointegrating vectors. Lag selection is based on information criteria. The results are reported in Table 2 and conclude to the existence of two cointegrating vectors. Consequently, the rest of the paper is based on $r=2$.

Table 2: Panel cointegration test

\begin{tabular}{ccccc} 
& \multicolumn{3}{c}{ Crit Val } \\
Rank $(r)$ & T-stat & $10 \%$ & $5 \%$ & $1 \%$ \\
\hline 0 & 188.56 & 160.44 & 176.67 & 209.80 \\
1 & 114.98 & 79.26 & 92.21 & 117.85 \\
2 & 3.48 & 16.18 & 22.82 & 39.77 \\
\hline
\end{tabular}

Maximum likelihood estimates of the matrix $\Pi_{B}$ with $r=2$ are reported in Table 3 for all countries in our dataset. At a first glance, these results suggest that there may 
exist positive long run causality from financial development to economic growth since coefficients on BANK and/or INST are of opposite signs to that on GDP in the first equation (with dependent variable $\Delta G D P_{t}$ ) for all countries. For a similar reason, the reverse positive causation from economic growth to financial development is not excluded. Lastly, long run causality (mostly negative) between financial variables is also possible. This is the purpose of the next subsection to determine the significance of all the potential long run relationships which may exist between GDP, BANK and INST.

Table 3: Estimations of $\Pi_{i}$ under $r=2$ 


\begin{tabular}{|c|c|c|c|c|}
\hline \multicolumn{5}{|l|}{ Belgium } \\
\hline & & $\mathrm{GDP}_{\mathrm{t}-1}$ & BANK $_{t-1}$ & $\mathrm{INST}_{\mathrm{t}-1}$ \\
\hline & $\Delta \mathrm{GDP}_{\mathrm{t}}$ & -0.033 & 0.002 & 0.003 \\
\hline & $\triangle$ BANK $_{\mathrm{t}}$ & 1.372 & -0.490 & -0.772 \\
\hline & $\triangle \mathrm{INST}_{\mathrm{t}}$ & 0.224 & -0.079 & -0.124 \\
\hline \multicolumn{5}{|l|}{ Canada } \\
\hline & & $G D P_{t-1}$ & BANK $_{t-1}$ & $\mathrm{INST}_{\mathrm{t}-1}$ \\
\hline & $\Delta \mathrm{GDP}_{\mathrm{t}}$ & -0.622 & 0.074 & 0.303 \\
\hline & $\triangle$ BANK $_{\mathrm{t}}$ & 0.521 & -0.053 & -0.572 \\
\hline & $\Delta \mathrm{INST}_{\mathrm{t}}$ & 1.275 & -0.151 & -0.653 \\
\hline \multicolumn{5}{|l|}{ Chile } \\
\hline & & $\mathrm{GDP}_{\mathrm{t}-1}$ & BANK $_{t-1}$ & $\mathrm{INST}_{\mathrm{t}-1}$ \\
\hline & $\Delta \mathrm{GDP}_{\mathrm{t}}$ & 0.071 & -0.069 & -0.544 \\
\hline & $\triangle$ BANK $_{\mathrm{t}}$ & 0.047 & -0.424 & 0.981 \\
\hline & $\triangle \mathrm{INST}_{\mathrm{t}}$ & 0.008 & -0.014 & -0.035 \\
\hline \multicolumn{5}{|l|}{ Japan } \\
\hline & & $G D P_{t-1}$ & BANK $_{t-1}$ & $\mathrm{INST}_{\mathrm{t}-1}$ \\
\hline & $\Delta \mathrm{GDP}_{\mathrm{t}}$ & -0.061 & 0.005 & -0.015 \\
\hline & $\triangle$ BANK $_{\mathrm{t}}$ & -0.242 & 0.065 & 0.401 \\
\hline & $\Delta \mathrm{INST}_{\mathrm{t}}$ & 0.253 & -0.077 & -0.512 \\
\hline \multicolumn{5}{|l|}{ Spain } \\
\hline & & $G D P_{t-1}$ & BANK $_{t-1}$ & $\mathrm{INST}_{\mathrm{t}-1}$ \\
\hline & $\Delta \mathrm{GDP}_{\mathrm{t}}$ & -0.071 & -0.009 & 0.103 \\
\hline & $\triangle$ BANK $_{t}$ & 0.028 & 0.194 & 0.008 \\
\hline & $\Delta \mathrm{INST}_{\mathrm{t}}$ & 0.515 & -0.002 & -0.764 \\
\hline \multicolumn{5}{|c|}{ United States } \\
\hline & & $G D P_{t-1}$ & BANK $_{t-1}$ & $\mathrm{INST}_{\mathrm{t}-1}$ \\
\hline & $\Delta \mathrm{GDP}_{\mathrm{t}}$ & -0.167 & 0.010 & 0.069 \\
\hline & $\triangle \mathrm{BANK}_{\mathrm{t}}$ & 0.090 & -0.165 & 0.263 \\
\hline & $\triangle \mathrm{INST}_{\mathrm{t}}$ & 0.622 & 0.100 & -0.516 \\
\hline
\end{tabular}

\section{Long run causality tests}

In this subsection, we explicitly test the significance of potential long run relationships between GDP, BANK and INST. We follow the procedure proposed by 
Toda and Phillips (1993, 1994). We first perform country by country weak exogeneity tests and tests related to the components of $\beta_{i}$ corresponding to the tested variables ${ }^{g}$. If both tests reject the null hypothesis, we further test the significance of the coefficient in $\alpha_{i} \beta_{i}$ which relates the variables of interest. If all these three tests are rejected, we conclude to the existence of long run causality from the explanatory to the explained variable for the tested country. Results of these tests are reported in Table 4.

\section{Discussion of the results}

Results from Tables 3 and 4 provide conclusions in terms of the long run causality between financial development and economic growth which differ from one country to another. This heterogeneity of results is in line with Demetriades and Hussein (1996) and Neusser and Kugler (1998). For Belgium and Canada, our results support the bi-directional hypothesis in which financial development (both banking development and institutional investors) fosters long run economic growth and at the same time economic growth positively influence the development of the financial sector in the long run. Chile and the United States are characterized by the demand-following relationship between finance and growth. Under this hypothesis, the financial sector of the economy develops in response to the demand from the real sector induced by economic growth. However, while economic growth promotes the development of both the banking sector and the institutional

\footnotetext{
${ }^{g}$ Note that the analysis focuses on country by country results but still within the system of Equation (5). Thus, the results account for the presence of cross-unit contemporaneous dependence.
} 
investors in Chile, it only affects the banking sector in the United States. The absence of causality from banking development and economic growth for the United States is in line with the results of Arestis and Demetriades (1997) and is consistent with the fact that the financial system in the United States is mainly stock market oriented. The case of Spain is somewhat particular since although it supports a long run causality running from banking development to economic growth, this relationship is shown to be negative (though slightly). The existence of potentially negative relationship between financial development and economic growth has already been highlighted by Gregorio and Guidotti (1995) for some countries. In the case of Japan, we find no significant long run relationship between financial and economic development. Lastly, our analysis also provides interesting results regarding the long run relationship between the banking sector and institutional investors. For 4 out of the 6 countries in our dataset (i.e. Belgium, Canada, Chile and Japan), we find a significant and negative long run relationship between BANK and INST. This would imply that in the long run one of our two indicators of financial development would develop to the detriment of the other suggesting that, in these countries, one of these two sources of risk mitigation would be favored against the other. 